\title{
Differences in fixation strength among constructs of atlantoaxial fixation
}

\author{
${ }^{*}$ Chih-Chang Chang, MD,,2 Wen-Cheng Huang, MD, PhD, ,,2 Tsung-Hsi Tu, MD,1,2,5 \\ Peng-Yuan Chang, MD, ${ }^{1,2,4}$ Li-Yu Fay, MD, ${ }^{1,2}$ Jau-Ching Wu, MD, PhD, ${ }^{1,2}$ and \\ Henrich Cheng, MD, PhD ${ }^{1-3}$
}

\begin{abstract}
'Department of Neurosurgery, Neurological Institute, Taipei Veterans General Hospital, Taipei; ${ }^{2}$ School of Medicine, National Yang-Ming University, Taipei; ${ }^{3}$ Institute of Pharmacology, National Yang-Ming University, Taipei; ${ }^{4}$ Department of Neurosurgery, Tao-Yuan General Hospital, Ministry of Health and Welfare, Tao-Yuan; and ${ }^{5}$ Taiwan International Graduate Program in Molecular Medicine, National Yang-Ming University and Academia Sinica, Taipei, Taiwan
\end{abstract}

OBJECTIVE To avoid jeopardizing an aberrant vertebral artery, there are three common options in placing a C2 screw, including pedicle, pars, and translaminar screws. Although biomechanical studies have demonstrated similar strength among these $\mathrm{C} 2$ screws in vitro, there are limited clinical data to address their differences in vivo. When different screws were placed in each side, few reports have compared the outcomes. The present study aimed to evaluate these multiple combinations of $\mathrm{C} 2$ screws.

METHODS Consecutive adult patients who underwent posterior atlantoaxial (AA) fixation were retrospectively reviewed. Every patient uniformly had bilateral C1 lateral mass screws in conjunction with 2 C2 screws (1 C2 screw on each side chosen among the three options: pedicle, pars, or translaminar screws, based on individualized anatomical consideration). These patients were then grouped according to the different combinations of $\mathrm{C} 2$ screws for comparison of the outcomes.

RESULTS A total of 63 patients were analyzed, with a mean follow-up of 34.3 months. There were five kinds of construct combinations of the C2 screws: 2 pedicle screws (the Ped-Ped group, $n=24$ ), 2 translaminar screws (the La-La group, $n=7$ ), 2 pars screws (the Pars-Pars group, $n=6$ ), 1 pedicle and 1 pars screw (the Ped-Pars group, $n=7$ ), and 1 pedicle and 1 translaminar screw (the Ped-La group, $n=19$ ). The rate of successful fixation in each of the groups was 100\%, 57.1\%, 100\%, 100\%, and 78.9\% (Ped-Ped, La-La, Par-Par, Ped-Par, and Ped-La, respectively). The patients who had no translaminar screw had a higher rate of success than those who had 1 or 2 translaminar screws $(100 \%$ vs $73.1 \%$, $p=0.0009$ ). Among the 5 kinds of construct combinations, 2 C2 pedicle screws (the Ped-Ped group) had higher rates of success than $1 \mathrm{C} 2$ pedicle and $1 \mathrm{C} 2$ translaminar screw (the Ped-La group, $p=0.018$ ). Overall, the rate of successful fixation was $87.3 \%$ (55/63). There were 7 patients ( 4 in the Ped-La group and 3 in the La-La group) who lost fixation/ reduction, and they all had at least 1 translaminar screw.

CONCLUSIONS In AA fixation, C2 pedicle or pars screws or a combination of both provided very high success rates. Involvement of 1 or 2 C2 translaminar screws in the construct significantly lowered success rates. Therefore, a C2 pars screw is recommended over a translaminar screw.

https://thejns.org/doi/abs/10.3171/2018.6.SPINE171390

KEYWORDS atlantoaxial fixation; pedicle screw; pars screw; translaminar screw; cervical

$\mathrm{T}$ TeChNiQues for atlantoaxial (AA) fixation have evolved tremendously in the past several decades. Laminar wiring and clamps have become less frequently used due to high rates of nonunion or persistent instability. Since 1979, when Magerl introduced the transarticular screw
(TAS),$^{11}$ the fusion rates of AA fixation have remarkably improved. However, a successful TAS fixation required adequate bone purchase of both $\mathrm{C} 1$ and $\mathrm{C} 2$ vertebrae along a steep trajectory, which usually needed reduction of the AA subluxation and was critically dependent on the width

ABBREVIATIONS $A A=$ atlantoaxial; $A D I=$ atlantodental interval; $H R V A=$ high-riding VA; $T A S=$ transarticular screw; $V A=$ vertebral artery. SUBMITTED December 21, 2017. ACCEPTED June 13, 2018.

${ }^{*}$ C.C.C. and W.C.H. contributed equally to this work. 
of the $\mathrm{C} 2$ pedicle. In narrow pedicles, there is frequently an aberrant (e.g., high-riding) course of a vertebral artery (VA), and complications of VA injury had been reportedly associated with TAS fixation. Then in 1994, Goel and Laheri ${ }^{9}$ reported a novel technique using a $\mathrm{C} 1$ lateral mass screw connected to a $\mathrm{C} 2$ pedicle screw with a plate. Subsequently, in 2001 Harms and Melcher ${ }^{10}$ reported similar techniques of AA fixation using a screw-and-rod construct. Both Goel's and Harm's techniques allowed placement of screws individually into the $\mathrm{C} 1$ and $\mathrm{C} 2$ vertebrae and thus reduced anatomical limitation and risk of VA injury.

Currently the screw-rod system connecting the $\mathrm{C} 1$ lateral mass and $\mathrm{C} 2$ pedicle screws is a widely accepted option for AA fixation. Furthermore, in patients with anomalous VA or bone anatomy, there are several technical modifications to place a $\mathrm{C} 2$ pedicle screw, including a shorter C2 pars screw and translaminar screw. ${ }^{8,28}$ Several biomechanical studies even demonstrated that all three kinds of $\mathrm{C} 2$ screws (i.e., pedicle, pars, and translaminar) had similar strength in vitro. Thus, a C2 pars or translaminar screw is often considered as an alternative/salvage method when there are safety concerns about placement of a $\mathrm{C} 2$ pedicle screw. However, there is lack of clinical data to actually compare the strength and durability of these different kinds of $\mathrm{C} 2$ screws in vivo. Moreover, there is little clinical data of patients who received a hybrid combination of these $\mathrm{C} 2$ screws for AA fixation. The present study aimed to evaluate the results of AA fixation when these different $\mathrm{C} 2$ (pars, pedicle, and translaminar) screws and combinations of them were used.

\section{Methods}

All clinical and radiological data of consecutive adult patients who underwent AA fixation with a screw-rod system were retrospectively reviewed. The surgical indications included C1-2 subluxation or instability, caused by trauma, developmental anomaly, degeneration, or other rheumatic disorders.

\section{Preoperative Management and Radiological Assessment}

Preoperative radiological examinations included cervical spine anteroposterior and static lateral radiography, dynamic lateral radiography, MRI, and CT. For patients who had easily reducible AA subluxation, halo-vest immobilization was applied and reduction was confirmed by lateral radiographs prior to the operation. For patients whose AA subluxation was fixed on the dynamic lateral radiographs, halo traction was applied routinely in the intensive care unit. Adjustments of the traction direction and incremental force according to serial cervical spine lateral radiographs were made with a gradual increase of counterweight until satisfactory reduction was achieved. If the halo traction failed to achieve adequate reduction of the AA complex, either anterior decompression (odontoidectomy), posterior decompression (laminectomy), or both were performed with AA fixation. Successful reduction was considered when an atlantodental interval (ADI) $<3 \mathrm{~mm}$ was achieved in nonrheumatic arthritis patients or $\mathrm{ADI}<5 \mathrm{~mm}$ was achieved in patients with rheumatic arthritis on cervical lateral dynamic radiographs.

\section{Operative Techniques}

Patients were taken to the operating room with halovest immobilization. After induction of general anesthesia, the patients were put in a prone position with the halo ring connected to a Mayfield headholder system. Then, a standard open posterior approach to the cervical spine was performed via midline skin incision. The neck muscles were dissected and detached with subperiosteal dissection for adequate exposure of cervical laminae, including $\mathrm{C} 1$ and $\mathrm{C} 2$. The $\mathrm{C} 1$ lateral mass screws were then placed manually using the anatomical references. The choice of either $\mathrm{C} 2$ pedicle, pars, or translaminar screws was based on preoperative CT evaluation and measurement of the width of $\mathrm{C} 2$ pedicles, and also the surgeons' preferences. These $\mathrm{C} 2$ pedicle, pars, or translaminar screws were then placed using the standard techniques described in previous publications..$^{10,16,28}$ Intraoperative fluoroscopy was used for confirmation of screw placement. In patients who needed no laminectomy, sublaminar wiring was performed with titanium soft wires for autologous bone graft, harvested from either the C7 spinous process or iliac crest. For those patients who received $\mathrm{C} 1$ and/or $\mathrm{C} 2$ laminectomy, the autologous bone grafts (either the removed lamina or harvested from posterior superior iliac crest) were placed between the lateral masses of $\mathrm{C} 1$ and $\mathrm{C} 2$. After the operation, the halo vests were removed immediately in the operating room and changed to a Miami neck collar for support.

\section{Follow-Up Evaluations}

All patients were scheduled for follow-up evaluation of anteroposterior, lateral, and lateral dynamic radiographs on postoperative days 3-5 (without dynamic views) and at $1.5,3,6,12,18$, and 24 months postoperatively. Moreover, postoperative CT scans were performed within 5 days after surgery and at 12 months postoperatively. Additional radiographic images, including MR images, would be arranged when considered informative during periodic follow-up evaluations. The neurological function of patients, including the severity of myelopathy if present, was also assessed during the clinic visits. Loss of fixation/reduction was determined by comparison of the lateral radiograph taken immediately postoperatively to that of follow-ups. The loss of initial reduction was determined by 1 of the 3 senior surgeons (W.C.H., J.C.W., and H.C.). They typically used the criteria of increased ADI of more than $1 \mathrm{~mm}$ on the follow-up lateral radiographs when compared to that of the immediate postoperative radiograph.

\section{Statistical Analysis}

Independent t-tests were used for analysis of continuous variables, and a Z-test for proportions was also used for analysis. A p value $<0.05$ was considered statistically significant. In the text and tables, the mean value is presented with standard deviation.

\section{Results \\ Demographics}

A total of 63 consecutive patients with AA instability 
TABLE 1. Summary of 63 patients with AA instability

\begin{tabular}{|c|c|}
\hline Variable & Value \\
\hline \multicolumn{2}{|l|}{ Demographics ( $n=63$ ) } \\
\hline Mean age \pm SD, yrs & $58.3 \pm 18.8$ \\
\hline Males, $\mathrm{n}(\%)$ & $37(58.7)$ \\
\hline Mean follow up, mos & 34.3 \\
\hline \multicolumn{2}{|l|}{ Pathology, $n(\%)$} \\
\hline Degeneration & $25(39.7)$ \\
\hline Trauma (acute/chronic) & $29(46)$ \\
\hline Rheumatoid arthritis & $7(11.1)$ \\
\hline Developmental anomaly & $2(3.2)$ \\
\hline \multicolumn{2}{|l|}{ Screw construct combinations, $\mathrm{n}(\%)$} \\
\hline Ped-Ped & $24(38.1)$ \\
\hline La-La & 7 (11.1) \\
\hline Par-Par & $6(9.5)$ \\
\hline Ped-Par & $7(11.1)$ \\
\hline Ped-La & $19(30.2)$ \\
\hline \multicolumn{2}{|l|}{ Adjuvant operations, $\mathrm{n}(\%)$} \\
\hline C1 laminectomy & $12(19)$ \\
\hline C1-2 laminectomy & $6(9.5)$ \\
\hline Odontoidectomy + C1 laminectomy & $3(4.8)$ \\
\hline Posterior wiring & $42(66.7)$ \\
\hline \multicolumn{2}{|l|}{ Complications, n (\%) } \\
\hline Surgical site infection & $1(1.6)$ \\
\hline CSF leakage & $1(1.6)$ \\
\hline C1 screw fracture & $2(3.2)$ \\
\hline Vascular injury & $0(0)$ \\
\hline \multicolumn{2}{|l|}{ Outcomes } \\
\hline Rigid fixation/arthrodesis, n (\%) & $55(87.3)$ \\
\hline
\end{tabular}

who underwent posterior AA fixation using the screw-rod techniques at our Neurological Institute were retrospectively analyzed. There were 26 women and 37 men. The etiologies of AA instability included degeneration $(\mathrm{n}=$ $25)$, trauma $(n=29)$, rheumatoid arthritis $(n=7)$, and developmental anomaly $(\mathrm{n}=2$, which included 1 Down syndrome and 1 Klippel-Feil syndrome; Table 1). There were 21 adjuvant decompressive procedures, including $\mathrm{C} 1$ and/ or $\mathrm{C} 2$ laminectomy in 18 patients and odontoidectomy in 3 patients.

\section{Screw Placement}

For screw placement in $\mathrm{Cl}$, every patient had polyaxial screws placed into the lateral masses bilaterally. For C2 screws, there were 3 options of trajectories (transpedicle, pars, and lamina), which resulted in 5 different combinations of the aforementioned 3 options of $\mathrm{C} 2$ screws. Thus, a total of 5 groups of constructs according to the $\mathrm{C} 2$ screw trajectories were analyzed, including the 2 pedicle screws (the Ped-Ped group, $n=24$ ), 2 translaminar screws (the La-La group, $n=7$ ), 2 pars screws (the Par-Par group, $n=$ 6), a combination of 1 pedicle and 1 pars screw (the PedPar group, $\mathrm{n}=7$ ), and a combination of 1 pedicle and 1 translaminar screw (the Ped-La group, $\mathrm{n}=19$ ).
TABLE 2. Comparison of fixation results between different screw-rod constructs

\begin{tabular}{lrcl}
\hline \multicolumn{1}{c}{ Group } & N & Fixation Rate (\%) & p Value \\
\hline Ped-Ped & 24 & 100 & $0.0009^{*}$ \\
\hline Par-Par & 5 & 100 & \\
\hline Ped-Par & 7 & 100 & \\
\hline Ped-La & 19 & 78.9 & \\
\hline La-La & 7 & 57.1 & \\
\hline Subgroup & & & 0.018 \\
\hline \multicolumn{1}{c}{ Ped-Ped vs Ped-La } & & 0.00076 \\
\hline Ped-Ped vs La-La & & &
\end{tabular}

Sixty-two total patients; 1 patient excluded from analysis due to postoperative deep wound infection.

${ }^{*}$ Comparison between the first three groups (Ped-Ped, Par-Par, and Ped-Par) and the last 2 groups (Ped-La and La-La), $p=0.0009$.

\section{Outcomes}

At the last follow-up (mean 34.3 months), there were 55 patients who achieved fusion or rigid fixation that was confirmed by both dynamic lateral radiographs and CT during the follow-up. Overall, the successful fusion or fixation rate was $87.3 \%$ (55/63). There were 7 patients who had lost reduction and fixation of $\mathrm{C} 1-2$, including 4 in the Ped-La group, and the other 3 in the La-La group. The individual rate of successful fusion or fixation of each group was $100 \%, 57.1 \%, 100 \%, 100 \%$, and $78.9 \%$ in the Ped-Ped, La-La, Par-Par, Ped-Par, and Ped-La group, respectively (Table 2).

Among these constructs of AA fixation, involvement of either 1 (unilateral) or 2 (bilateral) translaminar screws yielded significantly lower rates of successful fusion and fixation $(100 \%$ vs $78.9 \%$ or $57.1 \%, p=0.0009$, Table 2$)$. Furthermore, there were no differences in the rate of successful fusion or fixation in patients with bilateral $\mathrm{C} 2$ pedicle screws, bilateral pars screws, or 1 pedicle plus 1 pars screw on the other side (all 100\% successful). In a subgroup analysis, the Ped-Ped group had superior results compared with the Ped-La and La-La groups ( $\mathrm{p}=0.018$ and 0.00076 , respectively). In summary, patients who had no translaminar screw had significantly higher success rates of maintaining reduction, rigid fixation, and fusion of the C1-2 vertebrae than those who had 1 or 2 translaminar screws (100\% vs $73.1 \%$ ). All patients in the series used autologous bone grafts and demineralized bone matrix as bone graft extenders. None of the surgeries used bone morphological proteins. Commonly, the loss of reduction would be identified during the 6 - or 12 -week postoperative follow-up evaluation (average 1.8 months)

In this series, 42 patients (66.7\%) underwent sublaminar wiring and interlaminar bone grafting (the modified Gallie technique). For those patients who underwent laminectomy of $\mathrm{C} 1$ or $\mathrm{C} 2(\mathrm{n}=21)$, bone grafts were placed posterolateral to the lateral masses of $\mathrm{C} 1$ and $\mathrm{C} 2$. However, there were no differences in the success rates of reduction, fixation, and fusion between the groups with wiring and nonwiring ( $92.7 \%$ vs $80.9 \%, p=0.17$; Table 3 ). In the current series, there were 4 patients who lost reduction in the Ped-La group, 2 of whom had posterior wiring. Also, there 
TABLE 3. Fixation outcome comparison between wiring and nonwiring groups

\begin{tabular}{lccc}
\hline & Wiring Group & Non-Wiring Group & p Value \\
\hline No. of cases & 41 & 21 & \\
\hline Fixation rate & $92.7 \%(38 / 41)$ & $80.9 \%(17 / 21)$ & 0.17 \\
\hline
\end{tabular}

Sixty-two total patients; 1 patient excluded from analysis due to postoperative deep wound infection.

were 3 patients who lost reduction in the La-La group, 1 of whom had posterior wiring.

\section{Complications}

Among the 63 patients in the series there was 1 deep wound infection, which required debridement and removal of the screws. Thus, the patient was removed from the analysis of fusion rates. There were no vascular (VA) injuries, neurological injuries, or other thromboembolic events. One intraoperative CSF leakage was encountered during placement of a $\mathrm{Cl}$ screw, but there were no consequences of CSF leakage. There were 2 patients (in the LaLa group) who experienced loss of reduction and subsequent $\mathrm{C} 1$ screw fracture. One patient had minor symtpoms that did not prompt us to perform a secondary operation during the follow-up period. The other patient experienced progressive subluxation, for which occipitocervical fusion was performed (Table 1).

\section{Illustrative Cases That Lost Reduction and Fixation Case 1}

A 50-year-old man had a history of trauma due to involvement in a motor vehicle accident about 10 years previously. He had experienced neck pain and bilateral hand numbness for the last 5 years. He presented with signs of mild myelopathy and progressive deterioration of the symptoms, while the radiological evaluations by MRI, CT, and dynamic lateral radiography (Fig. 1A-D) demonstrated os odontoideum with apparent instability. After reduction of C1-2 subluxation, he underwent AA fixation using the construct of bilateral lateral mass $\mathrm{C} 1$ screws and hybrid C2 laminar and pedicle screws, respectively. The postoperative radiological evaluations demonstrated complete reduction of the AA complex (Fig. 1E and F) until 5 weeks postoperatively (Fig. $1 \mathrm{G}$ and $\mathrm{H}$ ). He had minor symptoms of mild headaches and dizziness intermittently, so there was no revision surgery for the patient and the construct looked the same at the present time.
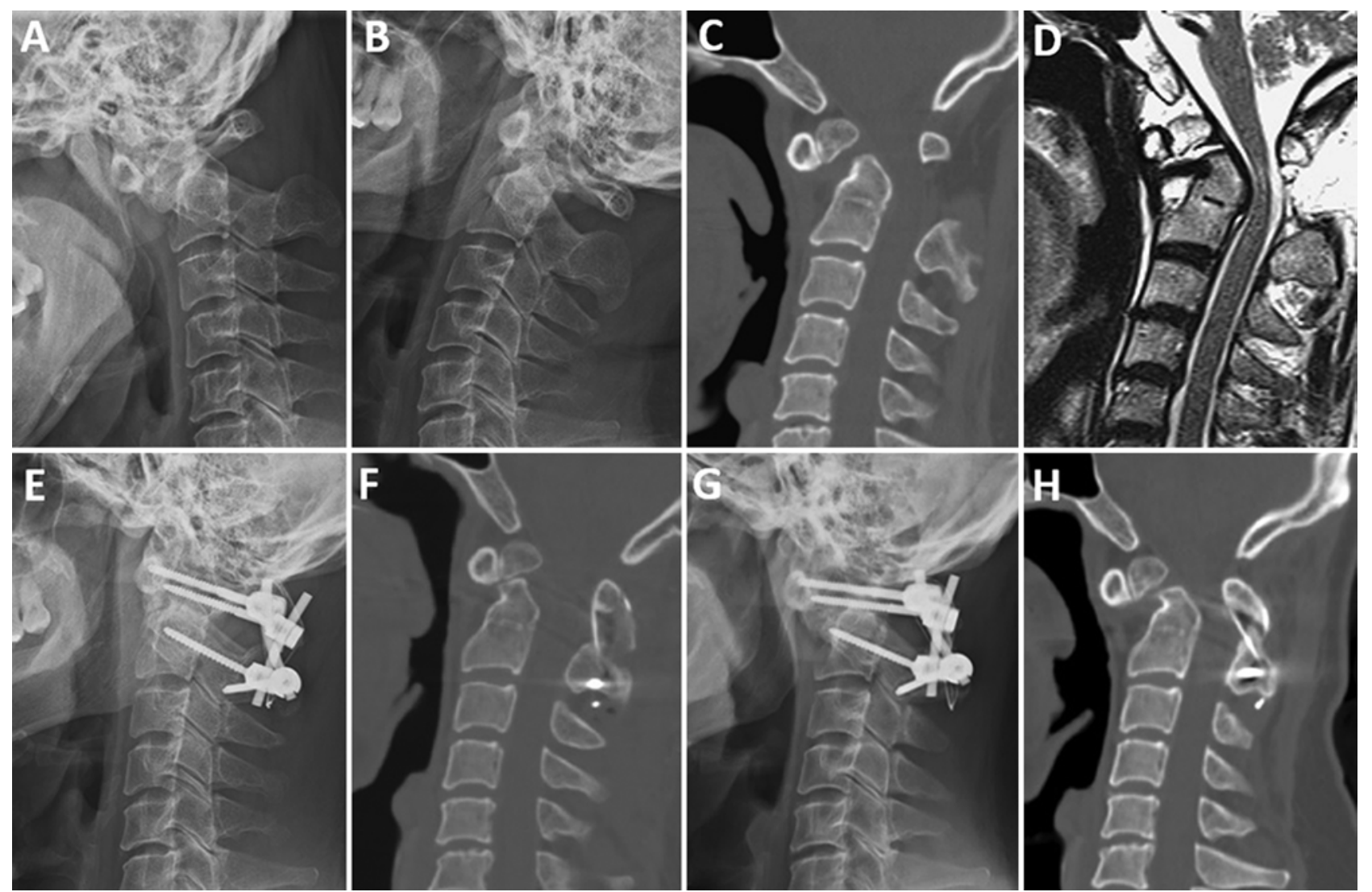

FIG. 1. Preoperative lateral dynamic radiographs (flexion and extension, $A$ and B), CT scan (C), and MR image (D) of a patient with chronic traumatic odontoid fracture. The patient underwent AA fixation with a combination of pedicle and translaminar screws in the $\mathrm{C} 2$ vertebra. The postoperative lateral radiographs and CT (E and F) demonstrated complete reduction, wiring, and autologous bone grafting. However, resubluxation was demonstrated at 1.5 months postoperatively on a lateral radiograph (G) and CT scan $(\mathbf{H})$. The patient had few symptoms and was managed conservatively and maintained follow-up to date. 

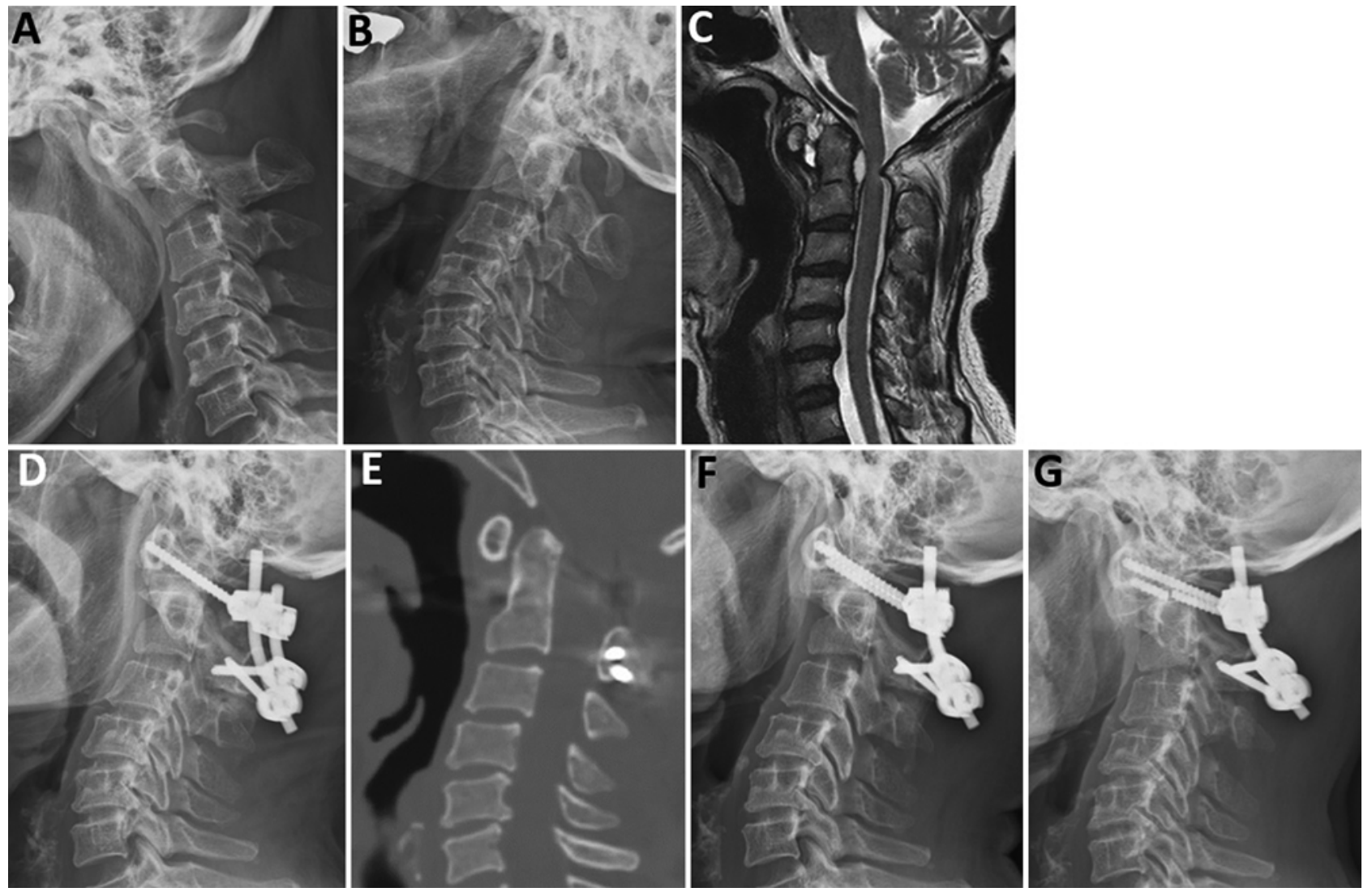

FIG. 2. Preoperative lateral dynamic radiographs (flexion and extension, $\mathbf{A}$ and $\mathbf{B}$ ) and $M R$ image $(\mathbf{C})$ of a patient with $A A$ subluxation who underwent fixation with bilateral $\mathrm{C} 1$ lateral mass screws and $\mathrm{C} 2$ translaminar screws. Reduction of the $\mathrm{AA}$ subluxation was achieved by surgery as shown on a lateral radiograph (D) and CT scan (E) 3 days postoperatively. However, there was gradual loss of reduction (F, 2-month postoperative lateral radiograph) and fracture of the $\mathrm{C} 1 \mathrm{screw}$ (G, 6-month postoperative lateral radiograph).

\section{Case 2}

A 63-year-old woman had right hemiparesis and numbness for 6 months, but she could not recall any trauma in the past year. The dynamic radiographs and MR images demonstrated AA subluxation and subsequent compression at the craniovertebral junction (Fig. 2A-C). She then underwent $\mathrm{C} 1$ laminectomy, reduction, and fixation with a construct involving $\mathrm{C} 2$ bilateral translaminar screws (Fig. 2D and E). Reduction was lost and demonstrated by images at 2 months postoperatively (Fig. 2F). Upon her visit at 6 months postoperatively, there was a broken $\mathrm{C} 1$ screw (Fig. 2G). The patient remained asymptomatic and therefore she did not receive a second surgery.

\section{Discussion}

To validate the use of different $\mathrm{C} 2$ screws in constructs for posterior AA fixation, the authors analyzed 63 consecutive adult patients (mean age 58.3 years) who needed fixation and reduction of AA subluxation. Every patient had bilateral $\mathrm{C} 1$ lateral mass screws in conjunction with 2 C2 screws as options and combinations of pedicle, pars, or translaminar screws, based on individualized anatomical consideration. Both clinical and radiological outcomes, including reduction and fusion rates, were compared at a mean follow-up of over 2.5 years (34.3 months). There were five kinds of construct combinations of the $\mathrm{C} 2$ screws in the series: 2 pedicle screws (the Ped-Ped group, $n=24$ ), 2 translaminar screws (the La-La group, $\mathrm{n}=7$ ), 2 pars screws (the Pars-Pars group, $\mathrm{n}=6$ ), 1 pedicle and 1 pars screw (the Ped-Pars group, $\mathrm{n}=7$ ), and 1 pedicle and 1 translaminar screw (the Ped-La group, $n=19$ ). The success rates of fixation were high when 2 pedicle screws, 2 pars screws, or 1 pedicle plus 1 pars screw were placed. However, the series clearly demonstrated that involvement of 2 or 1 translaminar screw significantly lowered the rate of success $(57.1 \%$ and $78.9 \%$, La-La and Ped-La, respectively). Significantly higher success rates of AA fixation were observed in patients who had no translaminar screw than those who had 1 or 2 translaminar screws in the screw-rod constructs $(100 \%$ vs $73.1 \%, p=0.0009)$. The choice of using a pars screw over a translaminar screw did not allow more complications, and the overall fusion rate was $87.3 \%$ $(55 / 63)$ in the series. Furthermore, among the 7 patients (4 in the Ped-La group and 3 in the La-La group) who lost reduction (loss of correction of previous subluxation) or failed to achieve arthrodesis, all had at least 1 translaminar screw. Therefore, the authors would recommend using a C2 pedicle or pars screw, or a combination of both, when attempts are made to use the screw-rod system for posterior AA fixation or reduction. Although there are many reports that have addressed the feasibility and biomechanical 
strength of C2 translaminar screws, this was the first paper to evaluate the outcomes of the combinations of the $\mathrm{C} 2$ screws, which are not uncommon in clinical practice due to anatomical variations for individual patients.

Posterior AA fixation has a crucial role in the management of diseases of the craniovertebral junction when there are concerns of stability. ${ }^{1,30}$ The techniques of posterior AA fixation have evolved through time. Various methods of wiring and tightening of a piece of bone to bridge the C1-2 laminas were widely adapted until the screws came into popularity years ago. The technique of C1-2 TAS was first introduced by Dr. Magerl in 1979. The TAS rapidly gained wide clinical adaption because of its improved success rates for arthrodesis of the AA complex. However, there had been persistent concerns of violation of the VA during screw insertion, which had been cited in the literature to be approximately $1.2 \%-4.1 \%$.,28,29 Although the overall incidence of compromise to the VA did not appear to be high, patients with aberrant anatomical course of the VA had particularly higher risks. Fortuitously, in the cases in which $\mathrm{C} 1$ and $\mathrm{C} 2$ fixation was required-for example, frequently patients with rheumatoid arthritis or congenital anomalies - the presence of a high-riding VA (HRVA) or thin $\mathrm{C} 2$ pedicles that could preclude safe placement of TAS was usually more common. The risk of VA injury was substantially reduced after individual placement of screws into the $\mathrm{C} 1$ and $\mathrm{C} 2$ vertebral bodies by Goel and Harms., ${ }^{9,10}$ Each polyaxial screw could be inserted according to the anatomical feature in each side of the $\mathrm{C} 1$ or $\mathrm{C} 2$ vertebral body, and thus this screw-rod construct would allow a better chance to avoid VA injury. By this individualized selection of screw trajectory and then connecting the screws with rods, the safety of AA fixation increased and yielded high fusion rates similar to that of the TAS technique.

To avoid violation of the VA while still providing adequate strength of the screw anchoring the axis (C2), there were several common options, including $\mathrm{C} 2$ pedicle screws, C2 pars screws, and C2 translaminar screws. Most spine surgeons would agree that bilateral $\mathrm{C} 2$ pedicle screws provide the longest screw purchase. However, insertion of a $\mathrm{C} 2$ pedicle screw was not always achievable because the course of the VA in the axis would correlate with the pedicle width and thus limit pedicle screw access. The VA anomalies, either extra- or intraosseous, were well reported. ${ }^{20,26,32}$ The HRVA was a well- known intraosseous anomaly that could be assessed through the thin-slice CT reconstruction. In the published literature, the incidence of HRVA in the normal population ranged from $10.1 \%$ to $32 \% .6,13,24-26$ However, the incidence increased enormously to $50 \%-70 \%$ in patients with AA subluxation, rheumatoid arthritis, or congenital skeletal anomalies (e.g., os odontoideum, Down syndrome, basilar invagination, and KlippelFeil syndrome). ${ }^{2,15,31,32}$ The issue of HRVA was particularly concerning in candidates for AA fixation, because these diseases frequently coincided with AA subluxation. Therefore, preoperative strategical planning was mandatory for the patient population. Furthermore, left VA dominance was reportedly observed in approximately $50 \%$ of the population, and its hypoplasia ranged from $1.9 \%$ to $11.6 \% .^{12,23}$ One should note that compromise to the VA in patients with the opposite VA hypoplasia could be catastrophic.

There were reports of biomechanical evaluations that addressed the strength of different choices of the screw trajectories for $\mathrm{C} 2$, including the pedicle, pars, and translaminar screws. ${ }^{14}$ Most spine surgeons would agree that the $\mathrm{C} 2$ pedicle screws had the greatest pullout strength, which was followed by translaminar or pars screws. When the entire construct connecting the $\mathrm{C} 1$ and $\mathrm{C} 2$ screws and rods was considered, the actual pullout strength and durability of the AA complex were difficult to compare. Some reports of meta-analyses demonstrated that all constructs of combinations had adequate force for stabilization of the AA subluxation in all axes, except that C2 translaminar screws were slightly inferior in lateral bending. ${ }^{3,5,17,22} \mathrm{Al}-$ though both pars and translaminar screws might yield less force of reduction than pedicle screws, these two types of screws significantly increased the chance to avoid VA injury. Furthermore, the actual clinical outcomes of combination of the constructs had never been compared in the literature. Several reports demonstrated that translaminar screws, when used bilaterally, had fusion rates ranging from $87.5 \%$ to $97.6 \% .^{4,18,19,21,27}$ Nevertheless, in a series of 30 patients with 59 laminar screws placed, 2 patients $(6.6 \%)$ experienced screw fracture and needed reoperations. In another series presented by Sciubba et al., 16 patients received AA fixation with $\mathrm{C} 2$ laminar screws, and there were 2 patients $(12.5 \%)$ who had reoperations due to screw pullout and pseudarthrosis. One larger series by Parker et al. ${ }^{19}$ compared C2 pedicle screws and C2 laminar screws in 167 patients. Among them, 31 patients were axial cases (C1-2 or C1-3, 16 laminar vs 15 pedicle screws) and 136 patients were subaxial cases (C2-caudal, 66 laminar vs 70 pedicle screws). The fusion rate in the axial group was $100 \%$. However, there were 4 cases of pseudarthrosis and screw pullout in the subaxial laminar screw group, which required reoperations. They therefore claimed that C2 laminar screws were equally effective as the pedicle screws when used for axial fusion, but inferior to the pedicle screws in subaxial fusion. Park et al. reported on 14 patients who underwent $\mathrm{C} 1$ lateral mass screw and C2 translaminar screw fixation, and radiographic bone fusion was demonstrated in 11 patients $(91.7 \%)$ at 6 months postoperatively. ${ }^{18}$ Furthermore, there was 1 bilateral $\mathrm{C} 1$ screw fracture in 52 patients who had AA fixation surgery using a total of 103 laminar screws.

Even with the polyaxial screw heads that allowed a wide range of tilting angles, connection of the $\mathrm{C} 1$ lateral mass screw to the $\mathrm{C} 2$ translaminar screw frequently required excessive bending of the rods. As proposed by Wright, ${ }^{28}$ the $\mathrm{C} 1$ screw and $\mathrm{C} 2$ translaminar screw were a unique construct of AA fixation. The construct connected one side of the $\mathrm{C} 1$ lateral mass screw head to the ipsilateral C2 laminar screw head that was actually inserted into the contralateral C2 lamina. Therefore, some surgeons called the C2 screw a crossing laminar screw. In fact, its unique entry point and the relatively diagonal trajectory of the $\mathrm{C} 2$ translaminar screw specifically made the connection difficult to achieve. After the assembly was accomplished, the polyaxial screw heads of the laminar screws would be dorsal to the instantaneous axis of rotation of the spine in multiple planes; this might adversely affect the construct. This could account for the poor lateral bending strength in biomechanical studies. The aforementioned features 

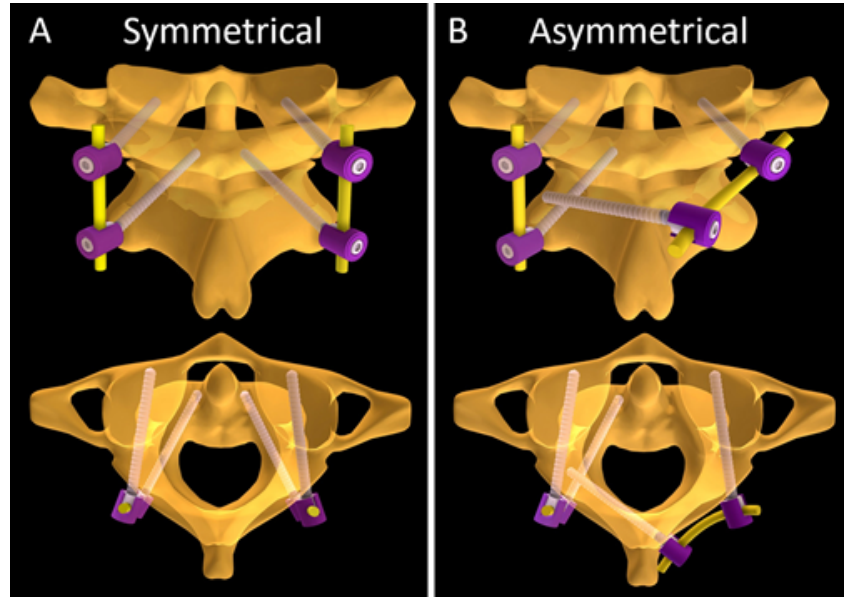

FIG. 3. Comparison of the symmetry between constructs: Ped-Ped (A) and Ped-La (B). Copyright Shao-Yen Huang. Interactive 3D version: https://sketchfab.com/Taroyen. Published with permission. Figure is available in color online only.

might predispose constructs that involve a $\mathrm{C} 2$ translaminar screw to loosening, loss of reduction, or implant failure. Thus, some authors suggested using larger diameter screws with an additional fixation point to prevent implant failure. In the series of Park et al., a transverse connector was used and could substantially reduce overbending the rod and allow easier assembly of the construct. ${ }^{18}$ Sciubba et al. ${ }^{21}$ reported a method to apply ipsilateral laminar screws and made the construct into a noncrossing construct that might improve lateral bending strength. This theory might explain the suboptimal results in this series, as the fixation rate was $57.1 \%$ and $78.9 \%$ in the La-La group and the Ped-La group, respectively. Placement of a strong pedicle screw connected to a translaminar screw might be better than bilateral laminar screws because of the strong purchase of one side of the $\mathrm{C} 2$ vertebral body. However, as compared to other constructs, the Ped-La construct was the only one with an asymmetrical layout. The construct contained $1 \mathrm{C} 1$ lateral mass screw connected to an ipsilateral pedicle screw and the other $\mathrm{C} 1$ screw connected to a contralateral laminar screw (Fig. 3; for demonstration of the details about the constructs' asymmetry, please see https://sketchfab.com/TaroYen for interactive 3D images and an enhanced version of Fig. 3). Therefore, the reduction force was concentrated on one side of $\mathrm{C} 2$, and this unbalanced torque force would cost the construct resistance to axial rotation, lateral bending, and anterior translation.

There are limitations to this study. First, this was a nonrandomized retrospective study with a relatively small sample size. Particularly when the data were broken down into each of the combinations, the comparison could be improved if a greater number of patients was involved to determine definitive outcomes of AA fixation. Moreover, there could be differences in the angle, trajectory, and strength of the $\mathrm{C} 1$ screws that could affect the power of fixation. Lastly, in the subgroup analysis for results of posterior wiring and fixation, more cases are required to perform multivariate analysis, and the contribution of posterior wiring to the AA screw-rod construct requires validation by longer-term follow-up.

\section{Conclusions}

When using a screw-rod system for posterior AA fixation, $\mathrm{C} 2$ pedicle or pars screws or a combination of both provided very high success rates. Involvement of 1 or $2 \mathrm{C} 2$ translaminar screws in the construct significantly lowered the rate of success. Therefore, the pars screw is recommended over the translaminar screw if anatomically feasible.

\section{References}

1. Chang PY, Yen YS, Wu JC, Chang HK, Fay LY, Tu TH, et al: The importance of atlantoaxial fixation after odontoidectomy. J Neurosurg Spine 24:300-308, 2016

2. Chung SS, Lee CS, Chung HW, Kang CS: CT analysis of the axis for transarticular screw fixation of rheumatoid atlantoaxial instability. Skeletal Radiol 35:679-683, 2006

3. Claybrooks R, Kayanja M, Milks R, Benzel E: Atlantoaxial fusion: a biomechanical analysis of two $\mathrm{C} 1-\mathrm{C} 2$ fusion techniques. Spine J 7:682-688, 2007

4. Dorward IG, Wright NM: Seven years of experience with C2 translaminar screw fixation: clinical series and review of the literature. Neurosurgery 68:1491-1499, 2011

5. Du JY, Aichmair A, Kueper J, Wright T, Lebl DR: Biomechanical analysis of screw constructs for atlantoaxial fixation in cadavers: a systematic review and meta-analysis. J Neurosurg Spine 22:151-161, 2015

6. Elgafy H, Pompo F, Vela R, Elsamaloty HM: Ipsilateral arcuate foramen and high-riding vertebral artery: implication on C1-C2 instrumentation. Spine J 14:1351-1355, 2014

7. Elliott RE, Tanweer O, Boah A, Morsi A, Ma T, FrempongBoadu A, et al: Outcome comparison of atlantoaxial fusion with transarticular screws and screw-rod constructs: metaanalysis and review of literature. J Spinal Disord Tech 27:11-28, 2014

8. Elliott RE, Tanweer O, Boah A, Smith ML, Frempong-Boadu A: Comparison of safety and stability of C-2 pars and pedicle screws for atlantoaxial fusion: meta-analysis and review of the literature. J Neurosurg Spine 17:577-593, 2012

9. Goel A, Laheri V: Plate and screw fixation for atlanto-axial subluxation. Acta Neurochir (Wien) 129:47-53, 1994

10. Harms J, Melcher RP: Posterior C1-C2 fusion with polyaxial screw and rod fixation. Spine (Phila Pa 1976) 26:2467-2471, 2001

11. Jeanneret B, Magerl F: Primary posterior fusion $\mathrm{C} 1 / 2$ in odontoid fractures: indications, technique, and results of transarticular screw fixation. J Spinal Disord 5:464-475, 1992

12. Katsanos AH, Kosmidou M, Kyritsis AP, Giannopoulos S: Is vertebral artery hypoplasia a predisposing factor for posterior circulation cerebral ischemic events? A comprehensive review. Eur Neurol 70:78-83, 2013

13. Lee SH, Park DH, Kim SD, Huh DS, Kim KT: Analysis of 3-dimensional course of the intra-axial vertebral artery for C2 pedicle screw trajectory: a computed tomographic study. Spine (Phila Pa 1976) 39:E1010-E1014, 2014

14. Lehman RA Jr, Dmitriev AE, Helgeson MD, Sasso RC, Kuklo TR, Riew KD: Salvage of C2 pedicle and pars screws using the intralaminar technique: a biomechanical analysis. Spine (Phila Pa 1976) 33:960-965, 2008

15. Miyata M, Neo M, Ito H, Yoshida M, Miyaki K, Fujibayashi $\mathrm{S}$, et al: Is rheumatoid arthritis a risk factor for a high-riding vertebral artery? Spine (Phila Pa 1976) 33:2007-2011, 2008

16. Mummaneni PV, Haid RW: Atlantoaxial fixation: overview of all techniques. Neurol India 53:408-415, 2005

17. Park J, Scheer JK, Lim TJ, Deviren V, Ames CP: Biomechanical analysis of Goel technique for C1-2 fusion. J Neurosurg Spine 14:639-646, 2011

18. Park JS, Cho DC, Sung JK: Feasibility of C2 translaminar 
screw as an alternative or salvage of $\mathrm{C} 2$ pedicle screws in atlantoaxial instability. J Spinal Disord Tech 25:254-258, 2012

19. Parker SL, McGirt MJ, Garcés-Ambrossi GL, Mehta VA, Sciubba DM, Witham TF, et al: Translaminar versus pedicle screw fixation of $\mathrm{C} 2$ : comparison of surgical morbidity and accuracy of 313 consecutive screws. Neurosurgery 64 (5 Suppl 2):343-349, 2009

20. Salunke P, Futane S, Sahoo SK, Ghuman MS, Khandelwal N: Operative nuances to safeguard anomalous vertebral artery without compromising the surgery for congenital atlantoaxial dislocation: untying a tough knot between vessel and bone. $\mathbf{J}$ Neurosurg Spine 20:5-10, 2014

21. Sciubba DM, Noggle JC, Vellimana AK, Conway JE, Kretzer RM, Long DM, et al: Laminar screw fixation of the axis. J Neurosurg Spine 8:327-334, 2008

22. Su BW, Shimer AL, Chinthakunta S, Salloum K, Ames CP, Vaccaro AR, et al: Comparison of fatigue strength of $\mathrm{C} 2$ pedicle screws, $\mathrm{C} 2$ pars screws, and a hybrid construct in C1-C2 fixation. Spine (Phila Pa 1976) 39:E12-E19, 2014

23. Szárazová AS, Bartels E, Turčáni P: Vertebral artery hypoplasia and the posterior circulation stroke. Perspect Med 1:198-202, 2012

24. Vaněk P, Bradáč O, de Lacy P, Konopková R, Lacman J, Beneš V: Vertebral artery and osseous anomalies characteristic at the craniocervical junction diagnosed by CT and 3D CT angiography in normal Czech population: analysis of 511 consecutive patients. Neurosurg Rev 40:369-376, 2017

25. Wajanavisit W, Lertudomphonwanit T, Fuangfa P, Chanplakorn P, Kraiwattanapong C, Jaovisidha S: Prevalence of highriding vertebral artery and morphometry of $\mathrm{C} 2$ pedicles using a novel computed tomography reconstruction technique. Asian Spine J 10:1141-1148, 2016

26. Wakao N, Takeuchi M, Nishimura M, Riew KD, Kamiya M, Hirasawa A, et al: Vertebral artery variations and osseous anomaly at the C1-2 level diagnosed by 3D CT angiography in normal subjects. Neuroradiology 56:843-849, 2014

27. Wang MY: Cervical crossing laminar screws: early clinical results and complications. Neurosurgery 61 (5 Suppl 2):311-316, 2007

28. Wright NM: Translaminar rigid screw fixation of the axis. Technical note. J Neurosurg Spine 3:409-414, 2005
29. Wright NM, Lauryssen C: Vertebral artery injury in C1-2 transarticular screw fixation: results of a survey of the AANS/CNS section on disorders of the spine and peripheral nerves. J Neurosurg 88:634-640, 1998

30. Wu JC, Tu TH, Mummaneni PV: Techniques of atlantoaxial fixation and the resection of $\mathrm{C} 2$ nerve root. World Neurosurg 78:603-604, 2012

31. Xu S, Ruan S, Song X, Yu J, Xu J, Gong R: Evaluation of vertebral artery anomaly in basilar invagination and prevention of vascular injury during surgical intervention: CTA features and analysis. Eur Spine J 27:1286-1294, 2018

32. Yamazaki M, Okawa A, Furuya T, Sakuma T, Takahashi H, Kato K, et al: Anomalous vertebral arteries in the extra- and intraosseous regions of the craniovertebral junction visualized by 3-dimensional computed tomographic angiography: analysis of 100 consecutive surgical cases and review of the literature. Spine (Phila Pa 1976) 37:E1389-E1397, 2012

\section{Disclosures}

The authors report no conflict of interest concerning the materials or methods used in this study or the findings specified in this paper.

\section{Author Contributions}

Conception and design: Wu, CC Chang, Huang, Tu, PY Chang. Acquisition of data: CC Chang. Analysis and interpretation of data: Wu, CC Chang. Drafting the article: Wu. Critically revising the article: Wu. Reviewed submitted version of manuscript: Wu, CC Chang, Huang, Tu, PY Chang, Fay. Approved the final version of the manuscript on behalf of all authors: Wu. Statistical analysis: CC Chang. Administrative/technical/material support: Wu, Huang, Tu, PY Chang, Fay, Cheng. Study supervision: Wu, Huang, Cheng.

\section{Correspondence}

Jau-Ching Wu: Neurological Institute, Taipei Veterans General Hospital, Taipei, Taiwan. jauching@gmail.com. 